\title{
CRIMINALISTICS
}

Jill Hager Cocking, ${ }^{1,2}$ M.S.; Sgt. Ryan Turley, ${ }^{3}$ Viacheslav Y. Fofanov, ${ }^{1}$ Ph.D.; Kimberly Samuels-Crow, ${ }^{1}$

4 Ph.D.; Bruce Hungate, ${ }^{4,5}$ Ph.D.; Rebecca L. Mau, ${ }^{2}$ M.S.; Paul S. Keim, ${ }^{2}$ Ph.D.; J. Gregory Caporaso, ${ }^{6}$

5 Ph.D.; and Crystal Hepp, ${ }^{l}$ Ph.D.

\section{Forensic analysis of Soil Microbiomes: Linking Evidence to a}

7 Geographic Location*

$9 \quad{ }^{1}$ School of Informatics, Computing and Cyber Systems, Northern Arizona University, Flagstaff, Arizona

$10 \quad{ }^{2}$ Pathogen and Microbiome Institute, Northern Arizona University, Flagstaff, Arizona

$11{ }^{3}$ Flagstaff Police Department, Flagstaff, Arizona

$12 \quad{ }^{4}$ Department of Biological Sciences, Northern Arizona University, Flagstaff, Arizona

$13 \quad{ }^{5}$ Center for Ecosystem Science and Society, Northern Arizona University, Flagstaff, Arizona

$14{ }^{6}$ Center for Applied Microbiome Science, Pathogen and Microbiome Institute, Northern Arizona University,

15 Flagstaff, Arizona

$16 *$ Presented at the $71^{\text {st }}$ Annual Meeting of the American Academy of Forensic Sciences, February 18-23, 2019, in

17 Baltimore, MD.

ABSTRACT: Over the past two decades, advances in molecular biology have greatly expanded our understanding of microbiomes - the diverse assemblages of microorganisms that inhabit the human body as well as the world around us, and applications in microbiome science have become an active area of research. Differences in the diversity (i.e., richness) and composition of microbiomes has been found to be informative in varied areas of science, including human health, agronomy, and forensic science. Soil harbors microbiomes that vary based on many factors, including the geology of the soil (e.g., sand, silt, or 
In this study, a soil microbiome was extracted from the sock of a criminal suspect and compared to the microbiome of soil samples taken from locations traveled to by the suspect. The locations analyzed varied in their soil microbiome composition, and the microbiome profiled from the sock was found to be most similar to the location where the suspect was thought to have left the body of a murder victim. These results provide a case study illustrating that information contained in a soil microbiome may be applied to link evidence to the location where a crime took place, potentially serving as an investigative tool in law enforcement.

KEYWORDS: forensic science, microbiome, soil, QIIME 2, DNA, sock understanding of microbiomes, communities of different species of microscopic organisms whose metabolisms are tightly linked to one another, to their environments, or to their plant and animal hosts. These technological advances have led to our recent recognition that there are orders of magnitude more microbial species than were previously thought to have existed (1). This has led to a revolution in microbiology, with new sub-fields of science forming to understand the composition and functional activities of microbiomes. The microbiome of the skin and inside the human body varies substantially

44 depending on the body location sampled and has revealed itself as an important indicator of health (2). For example, individuals with chronic conditions like Crohn's Disease and chronic rhinosinusitis harbor gut (3) and sinus microbiomes (4), respectively, with lower richness (i.e., fewer different species present) than the microbiomes of healthy individuals. Similarly, individuals with acute viral gastroenteritis also have less diverse gut microbiomes (5). Although fecal supplementation following antibiotic treatment has seen fringe use in medicine since the 1950s (6), we are now beginning to formally develop applications of this knowledge in human health. For example, the transplantation of a healthy individual's gut microbiome into

51 a patient suffering from recurring Clostridium difficile infections is now becoming common (7). 
unique microbial fingerprint is left behind on the objects that we touch that objects, such as keyboards and computer mice, can be linked to their owner solely based on the microbes found on their surfaces (8). individual (9). Even time of death information may be gleaned from the succession of microbial communities which are involved in decomposition (10). Taken together, these studies suggest a role for microbiome science in forensics applications. microbial composition of a soil sample is driven by factors including the physicochemical properties of the soil (e.g., pH, salinity) $(11,12)$, environmental features (13), and land use (14), such that no two soil samples will ever be exactly alike. This variation between soils from different locations has proven to be specific enough to be potentially useful in forensic investigations (15).

We therefore hypothesized that soil extracted from a piece of evidence may provide sufficient information to link that evidence to the soil's source. was missing and presumed dead. A suspect was in custody but was not revealing the location of the missing woman. Using various investigative tools, the police knew where the suspect had traveled since being released on bail from the Flagstaff jail a few days earlier. The police were trying to decide whether to focus

71 their search efforts in the town of Mayer, Arizona (Yavapai County) or Williams, Arizona (Coconino

72 County), with a distance between the two of 87 to 118 miles depending on the route taken. A sock embedded

73 with soil, believed to have been worn by the suspect while not wearing a shoe, was in the custody of the

74 police. Their hope was that the sock could be analyzed and linked to one of the two locations to aid in

75 finding the body. During the following few days (before the microbiome analysis was completed), the body 76 was recovered in Mayer, Arizona. Even though the police no longer needed assistance with the recovery of 77 the body, we attempted to analyze soil embedded in the sock in order to compare it to various locations 78 around Yavapai and Coconino Counties in the state of Arizona to determine if the soil microbiome could 

community depending on location, we compared the bacterial community found on the sock with bacterial

81 communities found in multiple soil samples collected from locations traveled to by the suspect during the 82 days prior to his arrest.

\section{Methods}

Reference surface soil samples were obtained from 18 locations around Williams (Coconino County) and Mayer (Yavapai Country), Arizona (Table 1). Locations were selected because they were

87 either near the site where the body was found (Fig. 1) or were places the suspect was known to have traveled in the days after he was last seen with the victim. Five soil samples collected from other locations in Arizona were also obtained from the Center for Ecosystem Science and Society (Ecoss) at Northern Arizona University to serve as additional reference samples (the "Ecoss reference samples"). Together this resulted in 23 reference samples where K1-11 and K13 refer to the Mayer soil samples, K12, K14-16, and K18 refer

TABLE 1- Information for samples used for analysis.

\begin{tabular}{|c|l|}
\hline Sample Name & Description \\
\hline Q1 & small cutting from sock, ball of foot area \\
\hline Q2 & small cutting from sock, heel area \\
\hline Q3 & swabbing of visibly dirt-covered area of sock for 3 minutes \\
\hline Q4 & swabbing of visibly dirt-covered area of sock for 3 minutes \\
\hline K1 & soil, right off highway Mayer, AZ \\
\hline K2 & soil, Road by trailer of owner of land where body was found, Mayer, AZ \\
\hline K3 & soil, off Road A, Mayer, AZ \\
\hline K4 & soil, dry, cracked ground near where body was found, Mayer, AZ \\
\hline K5 & soil, near body site, Mayer, AZ \\
\hline K6 & soil, 5 ft west of body site decomposition area, Mayer, AZ \\
\hline &
\end{tabular}


bioRxiv preprint doi: https://doi.org/10.1101/2020.07.10.198044; this version posted July 12, 2020. The copyright holder for this preprint (which was not certified by peer review) is the author/funder, who has granted bioRxiv a license to display the preprint in perpetuity. It is made available under aCC-BY-NC-ND 4.0 International license.

\begin{tabular}{|c|c|}
\hline K7 & soil, $5 \mathrm{ft}$ north of body site decomposition area, Mayer, $\mathrm{AZ}$ \\
\hline K8 & soil, $5 \mathrm{ft}$ east of body site decomposition area, Mayer, $\mathrm{AZ}$ \\
\hline K9 & soil, body site with visual decomposition residue, Mayer, AZ \\
\hline K10 & soil, body site with visual decomposition residue, Mayer, $A Z$ \\
\hline K11 & soil, behind body site, more plants, Mayer, AZ \\
\hline K12 & soil, Williams, AZ \\
\hline K13 & soil, $5 \mathrm{ft}$ south of body site decomposition area, Mayer, $\mathrm{AZ}$ \\
\hline K14 & soil, Williams, AZ \\
\hline K15 & soil, off Forest Service Road, Williams, AZ \\
\hline K16 & soil, Forest Service Road, Williams, AZ \\
\hline K17 & Soil, Chino Valley, AZ \\
\hline K18 & Soil, Williams, AZ \\
\hline W0.GL.1 & Grassland site of C. Hart Merriam Gradient, Northern Arizona \\
\hline W0.PJ.1 & Pinyon-Juniper site of C. Hart Merriam Gradient, Northern Arizona \\
\hline W0.MC.1 & Mixed Conifer site of C. Hart Merriam Gradient, Northern Arizona \\
\hline W0.PP.1 & Ponderosa Pine site of C. Hart Merriam Gradient, Northern Arizona \\
\hline 217 & Mixed Conifer site of C. Hart Merriam Gradient, Northern Arizona \\
\hline Reagent Blank Sock (RBsock) & Reagent Blank extracted alongside sock samples \\
\hline Reagent Blank Soil (RBsoil) & Reagent Blank extracted alongside soil samples \\
\hline
\end{tabular}




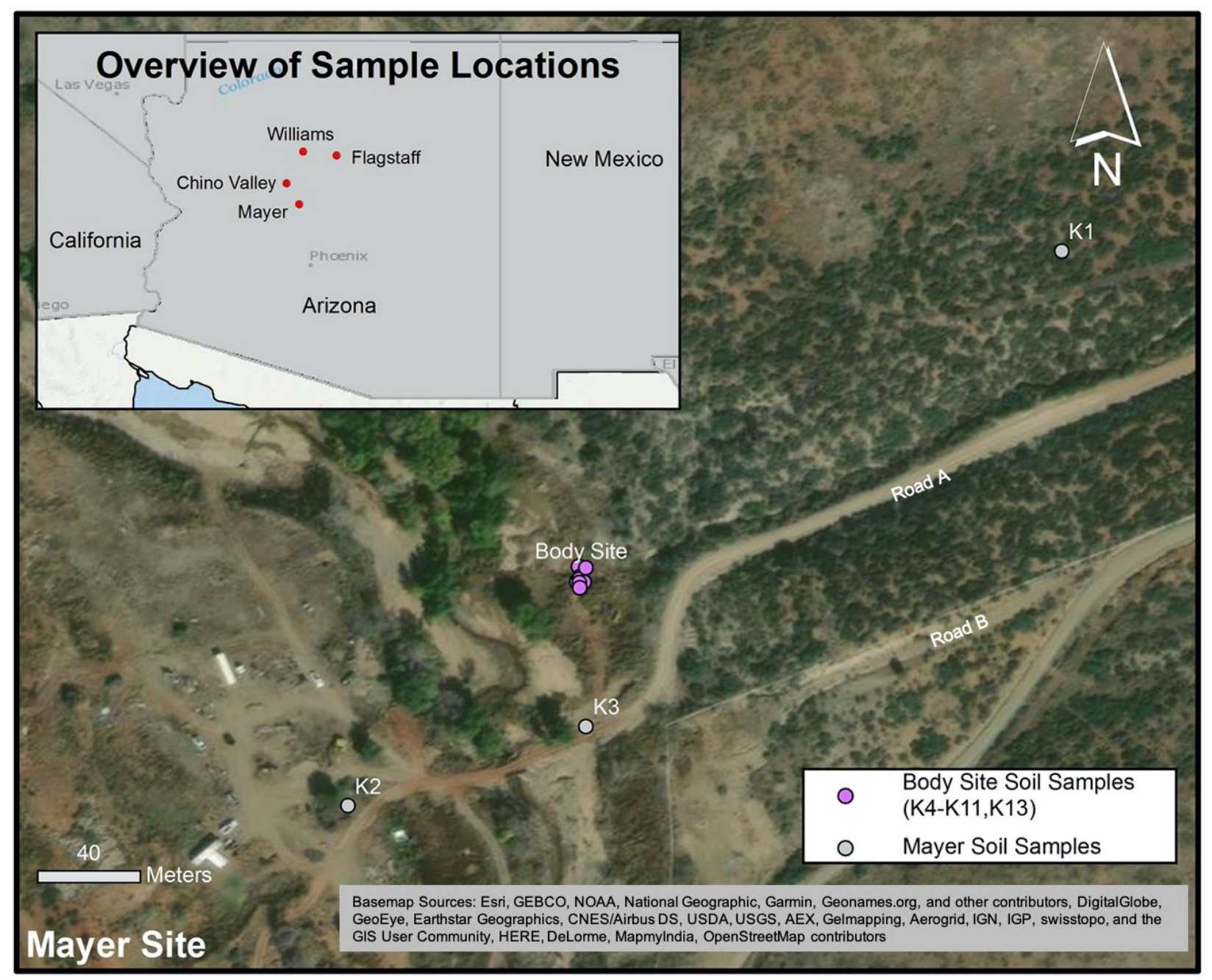
map shows geographic relationships between the Mayer site and other locations relevant to the case. Mayer Soil Samples include K1, K2, and K3. Body site soil samples include K4-K11 and K13 (Table 1). from the sock was performed in two ways with two replicates per extraction approach, yielding four query samples, referred to here as Q 1-4. Two DNA samples were extracted from cuttings of the sock itself 
were rubbed over the visibly soiled area of the outside of the sock for 3 minutes each, as described by Goga

108

(16). The swabs were then removed from the applicator and used for the remainder of the extractions. The extractions were performed using the Qiagen DNeasy ${ }^{\circledR}$ PowerSoil Kit (Qiagen, Germantown, MD) according to the manufacturer's protocol, with the following variations. The cuttings and swabs were placed at $65^{\circ} \mathrm{C}$ for 10 minutes followed by 2 minutes of horizontal vortexing at the maximum speed of the vortexer. The final elution volume was $100 \mu \mathrm{L}$.

For the reference soil samples (K1-18), approximately 0.25 grams of each of the 18 soil samples (Table 1) were added to a PowerBead tube containing solution $\mathrm{C} 1$. This tube was placed at $65^{\circ} \mathrm{C}$ for 10 minutes followed by 2 minutes of horizontal vortexing at maximum speed. The remainder of the extraction was performed according to the Qiagen DNeasy ${ }^{\circledR}$ PowerSoil Kit's manufacturer's instructions.

The EcoSS reference soil samples differed from the reference samples collected for this study in that they were collected below the soil surface $(0-10 \mathrm{~cm})$ while $\mathrm{K} 1-18$ were taken from the surface (as the surface soil would be the most likely to come into contact with the suspect's sock). There is known variation in soil microbiome composition depending on sampling depth (17), but these samples were included to provide additional background soils to which we could compare our query samples.

Extractions from Q1-4 and K1-18 were performed at different times in 2017. DNA was extracted from the EcoSS reference samples in 2014 and 2015 by using a MO BIO PowerSoil ${ }^{\mathrm{TM}}$ DNA Isolation Kit (Qiagen, Germantown, MD) and following the manufacturer's directions. Briefly, approximately $0.25 \mathrm{~g}$ of soil was added to the lysis tube and lysed using a MP Biomedicals FastPrep Homogenizer (MP Biomedicals, Irvine, CA). The final elution volume was $100 \mathrm{ul}$.

During the extractions for Q1-4 and K1-18, a reagent blank was taken through the entire process to monitor laboratory and extraction reagent contamination. For the sock samples, the reagent blank (RBsock) consisted of a cotton tipped swab moistened with UltraPure distilled $\mathrm{H}_{2} \mathrm{O}$ and cut with scissors used for the sock and handled with tweezers used for the sock extraction. The reagent blank was processed alongside 
the sock extractions. For the reference soil reagent blank (RBsoil), water was added to a weigh boat and then placed in a PowerBead tube and processed alongside the known soil samples. samples and sock samples, as well as the reagent blanks. This amplified DNA was then prepared for sequencing on the Illumina MiSeq instrument according to the protocol presented by Caporaso et al (18). The resulting sequences were analyzed using QIIME 2 microbiome bioinformatics platform (19). Sequence 137 quality control was performed using the denoise-paired method of QIIME 2's DADA2 (20) plugin with the following parameter settings: trunc_len_f 293; trunc_len_r 208; trim_left_f 6, trim_left_r 6. The resulting

142 using FastTree (24) (qiime phylogeny fasttree), and the tree was rooted by midpoint rooting (qiime

143 phylogeny midpoint-root). Weighted and unweighted UniFrac (25) distances were computed 100 times

144 each at an even sampling depth of 1000 sequences per sample. This low depth of coverage was used to

145 retain all samples in the analysis, and 100 iterations were run to confirm that conclusions were robust across

146 rarefied feature tables. These analyses were performed using the beta-rarefaction visualizer in QIIME 2's

147 diversity plugin. Sample tree illustrations were generated with ete3 (26).

\section{Results}

DNA was successfully extracted and the V4 region of the 16S rRNA gene was amplified from the 4 sock samples, the 2 reagent blanks, and the 23 reference soil samples. Weighted and unweighted UniFrac neighbor joining trees were constructed to evaluate the similarity of microbiomes (Fig. $2 \mathrm{a}$ and $2 \mathrm{~b}$, respectively). Briefly, the UniFrac metrics provide distances between pairs of microbiome samples. Smaller

153 values indicate that a pair of samples are similar in their composition, while larger values indicate that a 154 pair of samples are dissimilar in their composition. The unweighted UniFrac metric is considered a 
157 because it compares the abundances of different microbes in the samples. Because estimation of microbial

158 abundances is imperfect using the techniques applied for microbiome profiling, both weighted and

159 unweighted UniFrac metrics are often computed and compared. These metrics are applied to compute

160 distances between all pairs of microbiome samples, and the resulting distance matrix can be summarized

161 by constructing a neighbor joining tree. In this tree, samples are represented as the leaves (or tips), and the

162 length of the branches between leaves represents the distance between the samples.

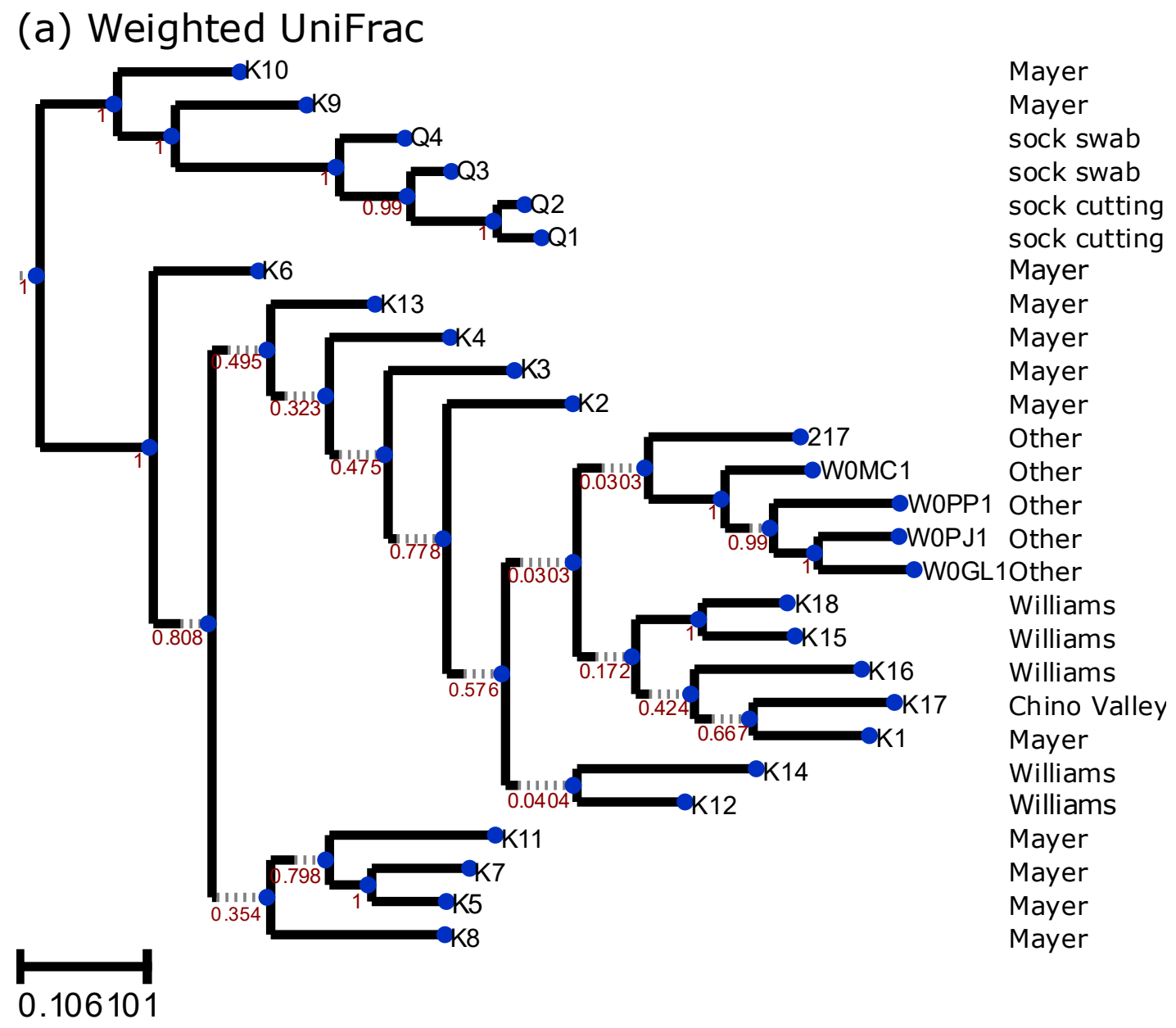




\section{(b) Unweighted UniFrac}

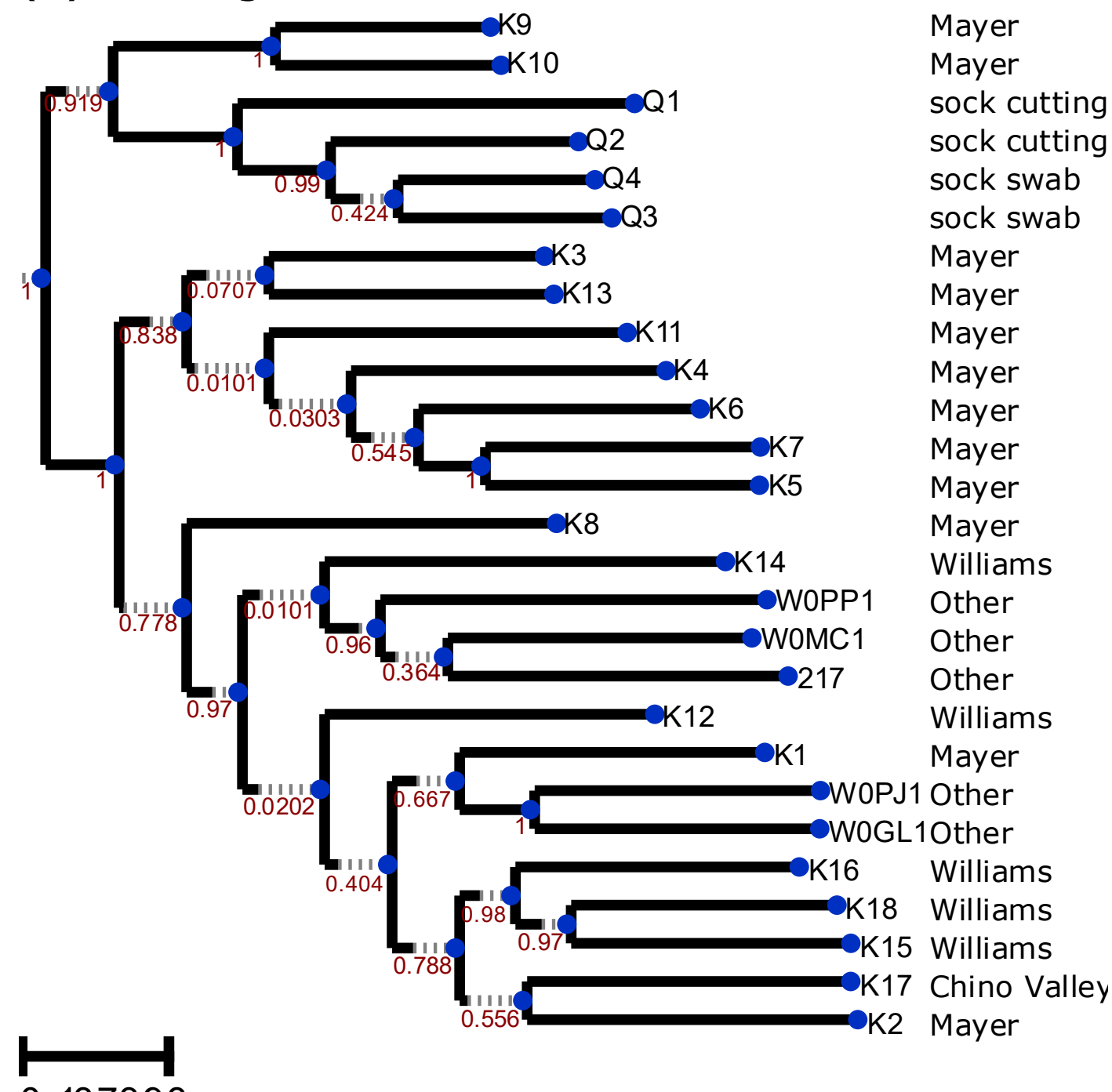

0.137398

FIG. 2- Neighbor joining trees illustrating (a) unweighted Unifrac and (b) weighted UniFrac distances

167 represents the dissimilarity between samples. Values above the internal nodes of the tree represent

168 jackknife support values, ranging between 0 and 1. Larger values indicate more robust groupings of

169 samples. 
Both the weighted and unweighted UniFrac neighbor joining trees illustrate that the sock samples

172 are all most similar to each other in composition, and that the closest soil samples are all from Mayer, where

173 the suspect left the remains of the victim. Clustering of the sock and Mayer soil samples was highly robust,

174 and suggest that the soil on the suspect's sock could have informed investigators of which cities should be

175 the focus of search efforts.

176

Analysis of the taxonomic composition revealed typical soil microorganisms for all soil samples

177 (Fig. 3). As would be expected, the dominant microorganisms in the sock sample were taxa commonly

178 found on human skin. Because the victim's body was left at sites K9 and K10, we were concerned that skin

179 microbes found at those sites would link those samples to the sock, irrespective of the soil microbial

180 composition. We therefore performed parallel analyses to those presented here after filtering the dominant

181 skin bacterial family found here, Staphylococcaceae, from the sock and soil samples. This resulted in the

182 taxonomic compositions presented in Fig. S2. The sock samples were still most similar to the Mayer

183 samples, even after removal of all Staphylococcaceae (Fig. S1). 
bioRxiv preprint doi: https://doi.org/10.1101/2020.07.10.198044; this version posted July 12,2020 . The copyright holder for this preprint (which was not certified by peer review) is the author/funder, who has granted bioRxiv a license to display the preprint in perpetuity. It is made available under aCC-BY-NC-ND 4.0 International license.

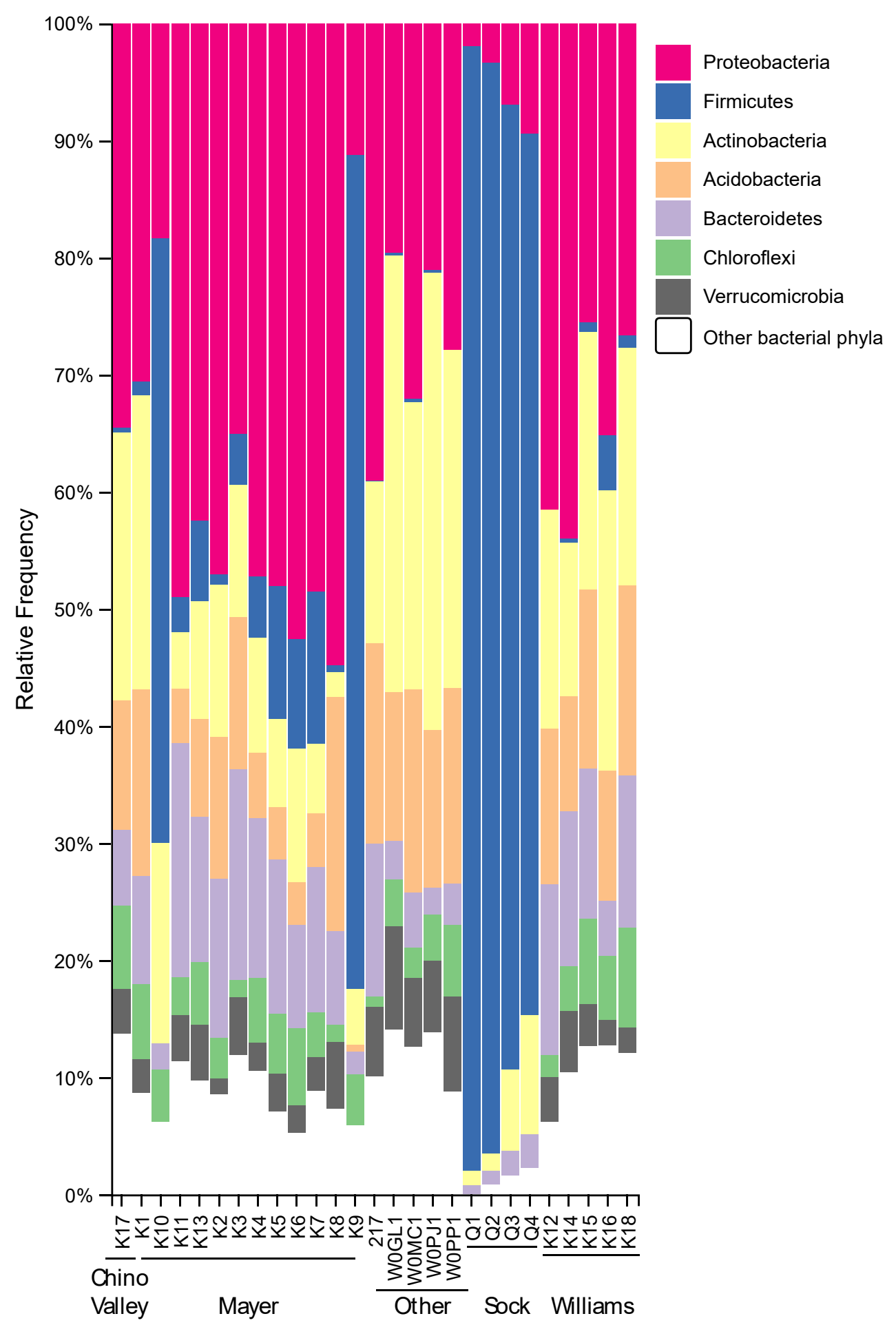


The sock swabbing technique obtained more of the soil profile with less human-associated microbes compared to the cutting of the sock method (Fig. 3), though all of the sock samples clustered together in our analyses, suggesting that either approach would have led us to the same conclusion (Fig. 2). Because the swabbing technique produced less human-associated microbes and was not destructive of the evidence, this approach is likely a better choice than extraction of DNA from the sock cuttings. are ubiquitous in any environment so careful monitoring of contamination from laboratory equipment and reagents is crucial (27). Reagent blanks were processed alongside both the sock and reference soil samples. Although bacteria were present in both reagent blanks, the composition and abundance varied greatly from the reference soil samples and the query sock samples (Fig. S3).

\section{Discussion} work. All analysis steps, including versions of software installed on the system when each step was run, are automatically tracked as metadata associated with its results. This would allow an expert to determine with complete certainty what computational steps were taken to generate a result. As DNA analysis workflows can be complex, this automated recording will provide experts with the information they need to be confident in a given result or to identify potential issues such as the presence of a software bug or suboptimal analysis step in a workflow that may impact conclusions drawn from the data. Data provenance can be

207 viewed for the results generated for this paper by loading the QIIME 2 results from Supplementary File 1 208 with QIIME 2 View (https://view.qiime2.org).

The ability to associate a piece of evidence to a location is a valuable tool to law enforcement. In 
211 days' time. Other evidence pointed to this individual having committed a murder, and both police and the

212 victim's family were anxious to discover the remains of the victim. With the police having narrowed down

213 some possible locations for the body site, we were able to link an item of evidence to the location where

214 the victim's body was left. This result was possible because we were able to create a small database of

215 locations known to have been visited by the suspect through police investigative techniques. Although the

216 victim's body was located with the assistance of the suspect, we believe that had this not happened, we

217 would have been able to advise law enforcement that the soil embedded in the suspect's sock most likely

218 came from the Mayer, Arizona area rather than other locations where soil was collected based on the data

219 presented here. In cases where areas coming in contact with the item of evidence are not known, a database

220 of known soils from across a county or even a state would be very useful.

Acknowledgements

223 Microbiome analysis and the QIIME 2 platform were partially funded by National Science Foundation 224 grant number 1565100 to JGC. Laboratory supplies, sequencing, and personnel time were covered by the 225 Arizona Board of Regents Technology Infrastructure Research Initiative Fund as startup funds to CMH.

226 Ecoss reference soil samples were collected with support by the National Science Foundation, Division of 227 Environmental Biology (grant number: DEB-1241094). 


\section{References}

1. Hugenholtz P. Exploring prokaryotic diversity in the genomic era. Genome Biology 2002; 3(2): reviews0003.1-reviews0003.8.

2. Huttenhower C, Gevers D, Knight R, Abubucker S, Badger JH, Chinwalla AT, et al. Structure, function and diversity of the healthy human microbiome. Nature 2012; 486: 207-214.

3. Gevers D, Kugathasan S, Denson LA, Vazquez-Baeza Y, Van Treuren W, Ren B, et al. The treatment-naïve microbiome in new-onset Crohn's disease. Cell Host Microbe 2014; 15(3): 382-392.

4. Cope EK, Goldberg AN, Pletcher SD, Lynch SV. Compositionally and functionally distinct sinus microbiota in chronic rhinosinusitis patients have immunological and clinically divergent consequences. Microbiome 2017; 5:53.

5. Chen SY, Tsai CN, Lee YS, et al. Intestinal microbiome in children with severe and complicated acute viral gastroenteritis. Sci Rep 2017;7:46130.

6. De Groot PF, Frissen MN, de Clercq NC, Nieuwdorp M. Fecal microbiota transplantation in metabolic syndrome: History, present and future. Gut Microbes 2017; 8 (3): 253-267.

7. Allegretti JR, Mullish BH, Kelly C, Fischer M. The evolution of the use of faecal microbiota transplantation and emerging therapeutic indications. The Lancet Therapeutics 2019; 394 (10196): 420-431.

8. Fierer N, Lauber CL, Zhou N, McDonald D, Costello EK, Knight R. Forensic identification using skin bacterial communities. PNAS 2010; 107 (14): 6477-6481.

9. Leake SL, Pagni M, Falquet L, Taroni F, Greub G. The salivary microbiome for differentiating individuals: proof of principle. Microbes Infect 2016; 18: 399-405.

10. Metcalf JL, Xu ZZ, Wiess S, Lax S, Van Treuren W, Hyde ER, et al. Microbial community assembly and metabolic function during mammalian corpse decomposition. Science 2016; 351: 158-162.

11. Ma J, Ibekwe AM, Yang CH, Crowley DE. Bacterial diversity and composition in major fresh produce growing soils affected by physiochemical properties and geographic locations. Sci Total Environ 2016; 563-564: 199-209.

12. Pershina EV, Ivanoca EA, Korvigo IO, Chirak EL, Sergaliev JH, Abakumoc EV, et al. Investigation of the core microbiome in main soil types from the East European plain. Sci Toal Environ 2018; 631-632: 1421-1430.

13. Neilson JW, Califf K, Cardona C, Copeland A, van Treuren W, Josephson KL, et al. Significant Impacts of Increasing Aridity of the Arid Soil Microbiome. mSystems 2017; 2 (3).

14. Lacerda-Junior GV, Noronha MF, Cabral L, Delforno TP, Sousa STPD, Fernandes-Junior PI, et al. Land Use and Seasonal Effects on the Soil Microbiome of a Brazilian Dry Forest. Front. Microbiol 2019.

15. Jesmok EM, Hopkins JM, Foran DR. Next-Generation Sequencing of the Bacterial 16S rRNA Gene for Forensic Soil Comparison: A Feasibility Study. Journal of Forensic Science 2016; 61 (3): 607-617.

16. Goga H. Comparison of bacterial DNA profiles of footwear insoles and soles of feet for the forensic discrimination of footwear owners. Int J Legal Med 2012; 126: 815-823.

17. Eilers KG, Debenport S, Anderson S, Fierer N. Digging deeper to find unique microbial communities: The strong effect of depth on the structure of bacterial and archaeal communities in soil. Soil Biology \& Biochemistry 2012; 50: 58-65. 
18. Caporaso JG, Lauber CL, Walters WA, Berg-Lyons D, Huntley J, Fierer N, et al. Ultra-highthroughput microbial community analysis on the Illumina HiSeq and MiSeq platforms. International Society for Microbial Ecology 2012; 6: 1621-1624.

19. Bolyen E, Rideout JR, Dillon MR, Bokulich NA, Abnet CC, Al-Ghalith GA, et al. Reproducible, interactive, scalable and extensible microbiome data science using QIIME 2. Nature Biotechnology 2019; 37: 852-857.

20. Callahan BJ, McMurdie PJ, Rosen MJ, Han AW, Johnson AA, Holmes SP. DADA2: Highresolution sample inference from Illumina amplicon data. Nature Methods 2016; 13: 581-583.

21. Bokulich NA, Kaehler BD, Rideout JR, Dillon M, Knight R, Huttley GA, Caporaso JG. Optimizing taxonomic classification of marker-gene amplicon sequences with QIIME 2's q2feature-classifier plugin. Microbiome 2018; 6 (90).

22. McDonald D, Price MN, Goodrich J, Nawrocki EP, DeSantis TZ, Probst A, et al. An improved Greengenes taxonomy with explicit ranks for ecological and evolutionary analyses of bacteria and archaea. ISME J. 2001; 6 (3): 610-618.

23. Katoh K, Standley DM. MAFFT Multiple sequence alignment software version 7: Improvements in performance and Usability. Molecular Biology and Evolution 2013; 30 (4): 772-780.

24. Price MN, Dehal PS, Arkin AP. FastTree 2 - Approximately Maximum-Likelihood Trees for Large Alignments. PLOS One 2010; https://doi.org/10.1371/journal.pone.0009490.

25. Lozupone CA, Hamady M, Kelley ST, Knight R. Quantitative and qualitative $\beta$ Diversity measures lead to different insights into factors that structure microbial communities. Applied and Environmental Microbiology 2007; 1576-1585.

26. Huerta-Cepas J, Serra F, Bork P. ETE 3: Reconstruction, analysis, and visualization of phylogenomic data. Mol Biol Evol 2016; 33(6): 1635-1638.

27. Salter SJ, Cox MJ, Turek EM, Calus ST, Cookson WO, Moffatt MF, et al. Reagent and laboratory contamination can critically impact sequence-based microbiome analyses. BMC Biol 2014; 12:87. 


\section{(a) Weighted UniFrac excluding all Staphylococcaceae}

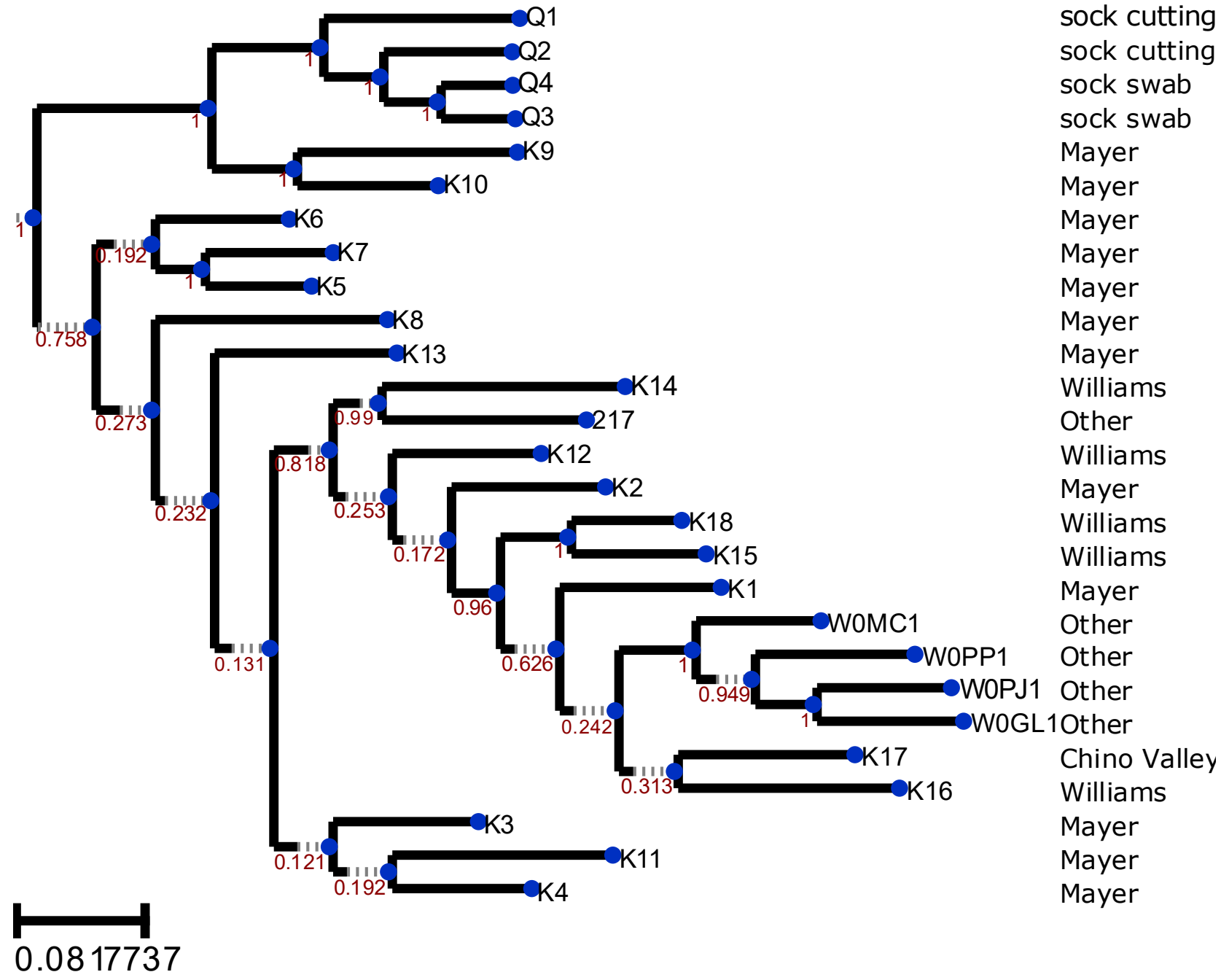




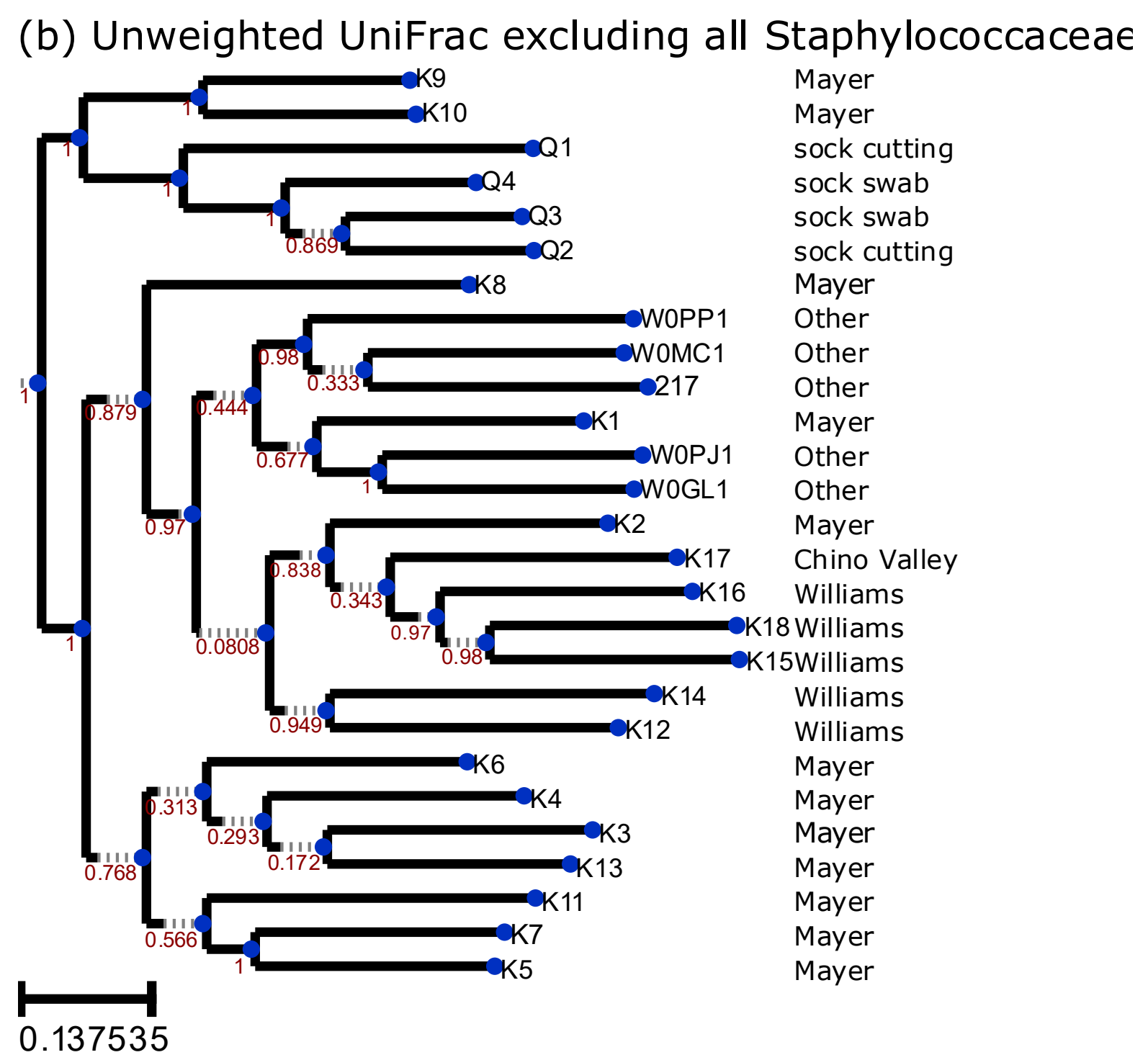


bioRxiv preprint doi: https://doi.org/10.1101/2020.07.10.198044; this version posted July 12, 2020. The copyright holder for this preprint (which was not certified by peer review) is the author/funder, who has granted bioRxiv a license to display the preprint in perpetuity. It is made available under aCC-BY-NC-ND 4.0 International license.

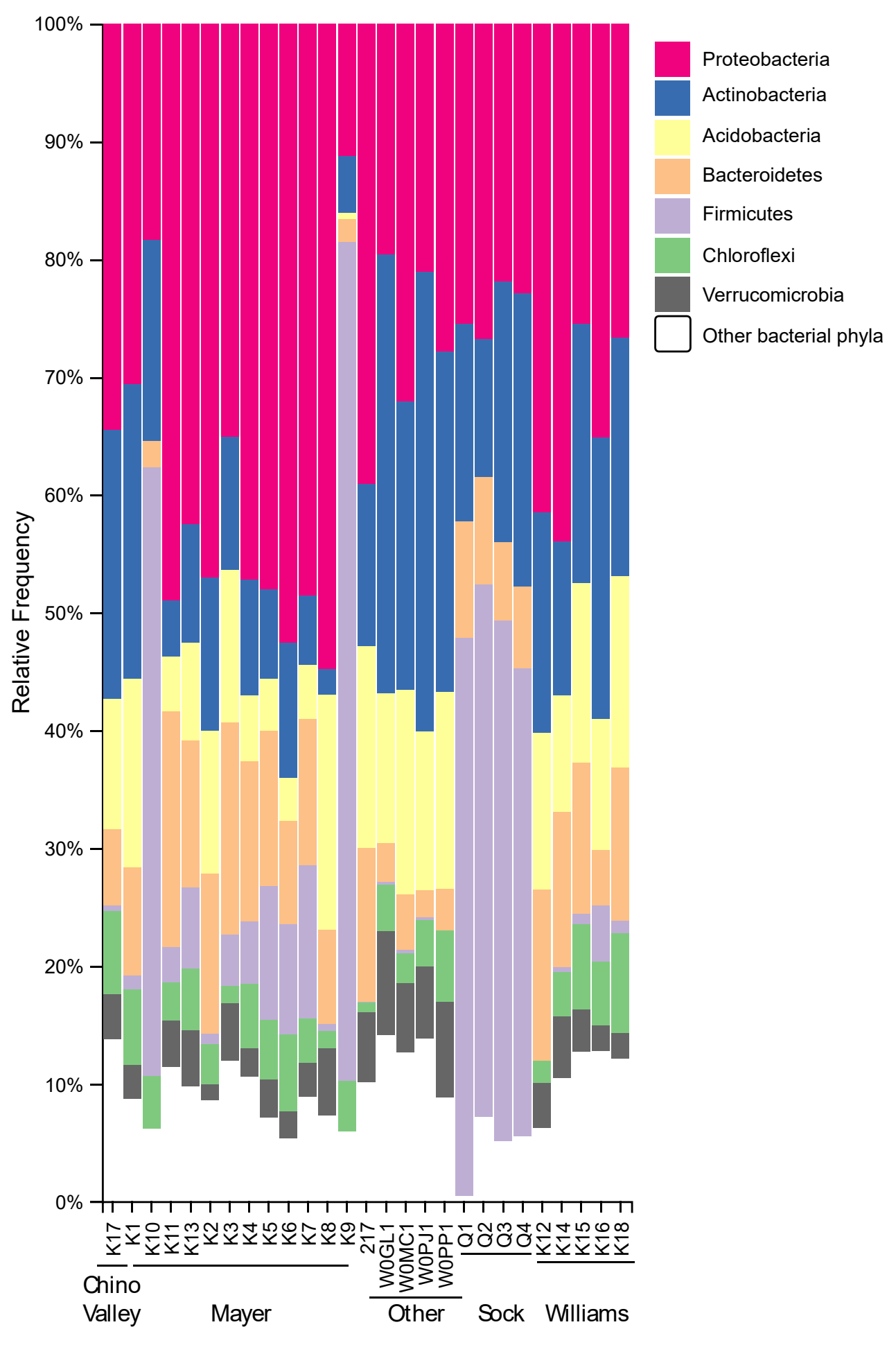

321 Microbiome taxonomic composition at the phylum levels for all samples after excluding all

322 Staphylococcaceae. 
bioRxiv preprint doi: https://doi.org/10.1101/2020.07.10.198044; this version posted July 12, 2020. The copyright holder for this preprint (which was not certified by peer review) is the author/funder, who has granted bioRxiv a license to display the preprint in perpetuity. It is made available under aCC-BY-NC-ND 4.0 International license.

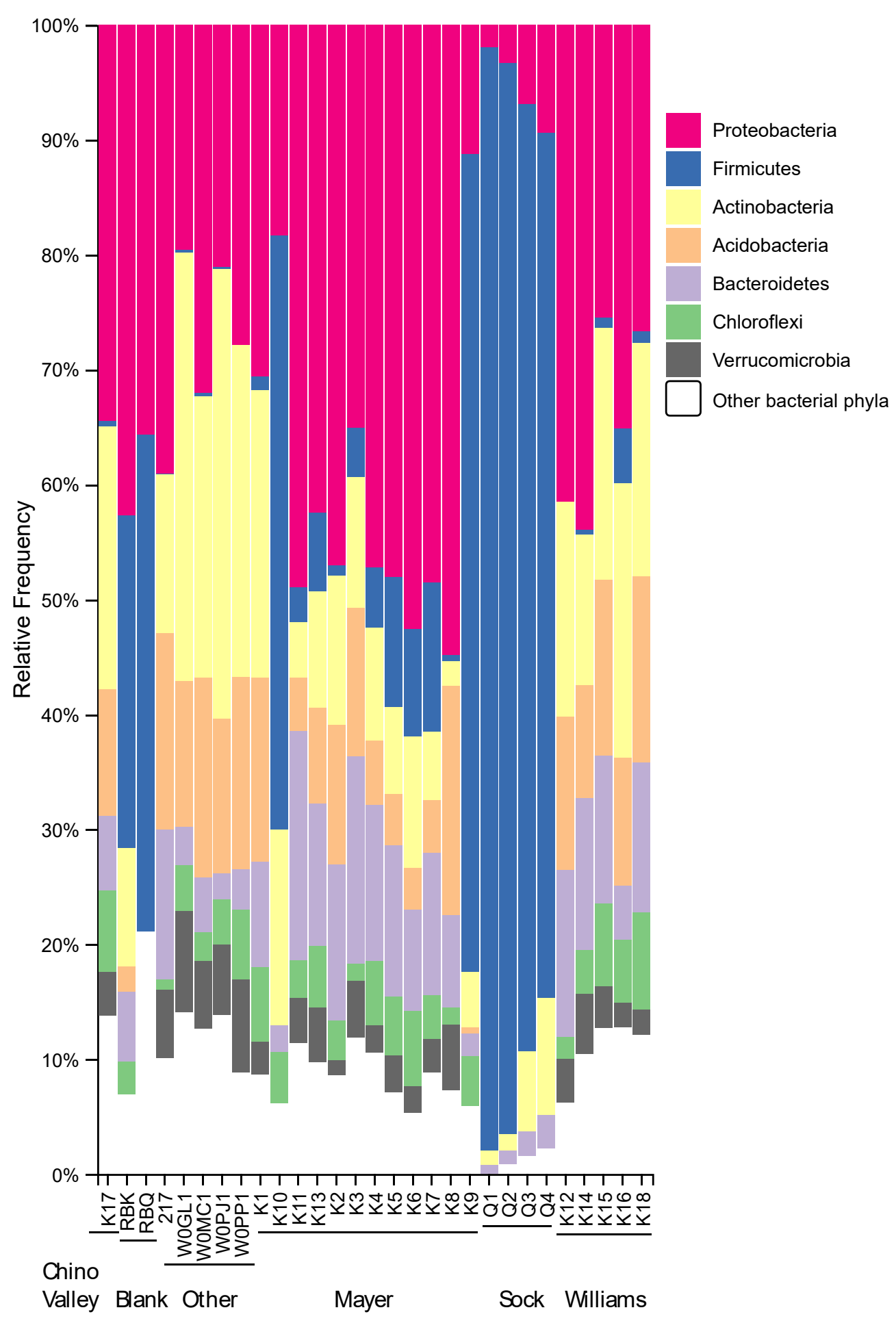

324 FIG. S3-Microbiome taxonomic composition at the phylum levels for all samples including reagent 
bioRxiv preprint doi: https://doi.org/10.1101/2020.07.10.198044; this version posted July 12, 2020. The copyright holder for this preprint (which was not certified by peer review) is the author/funder, who has granted bioRxiv a license to display the preprint in perpetuity. It is made available under aCC-BY-NC-ND 4.0 International license. 